\title{
PRIVACIÓN DE LA LIBERTAD EN EL SISTEMA PENAL ACUSATORIO: CARACTER EXCEPCIONAL
}

Abogado de la U. Nacional de Colombia y especializado en derecho penal y en derecho probatorio. Docente investigador de la Universidad Surcolombiana. Director del grupo de investigación Derecho y Derechos del Tercer milenio de la Universidad Surcolombiana.

\section{RESUMEN}

A partir del 1 de enero de 2005 entró a regir gradualmente en nuestro país un nuevo sistema de juzgamiento de marcada tendencia acusatoria que se recoge en la Ley 906 de 2004 y que adopta los lineamientos ordenados por la Constitución Política en cuanto a la estructura básica del proceso (Acto Legislativo 03 de 2002) y a la limitación de derechos fundamentales. En ese sentido, la nueva ley introduce criterios de interpretación constitucional de sus normas, especialmente de aquellas que de manera precisa tratan sobre derechos fundamentales y su limitación. La razonabilidad y la proporcionalidad son algunos de ellos. La privación de la libertad en dicho contexto normativo e interpretativo deviene expresamente como figura excepcional, no sólo cuando se materializa en una detención preventiva sino también en una captura con propósitos investigativos, previa a la solicitud de imposición de aquella.

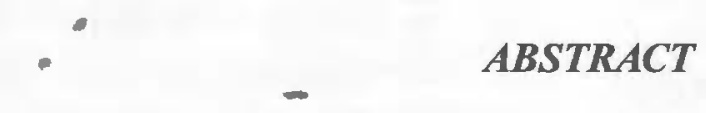

Starting on January 1st, 2005 in our country it was gradually in forced a new judging system characterized by a marked accusatory tendency. This system is part of law 906 of 2004 which adopted the constitution guidelines regarding the basic structure of the process (legislative act 03 of 2002) and limitation of fundamental rights. In this respect, the new law introduces constitutional interpretation criteria of its rules, especially of those about fundamental rights and their limitation. Reasonableness and proportion are some of them. Freedom deprivation in this regulating and interpretative context expressly becomes as an exceptional concept not only when it comes to fruition in preventive arrest but also in a capture for investigative purposes, prior to the request to impose it.

\section{PALABRAS CLAVES}

Constitucionalización del proceso penal; bloque de constitucionalidad; derecho a la libertad personal; detención preventiva; captura; razonabilidad; proporcionalidad; adecuación; necesidad; ponderación; excepcionalidad.

\section{KEY WORDS}

Writing into the constitution of the criminal process, block of constitutionality, right to personal freedom, preventive arrest, capture, reasonableness, proportion, adaptation, necessity, praise, exceptionality 


\section{PRESENTACIÓN}

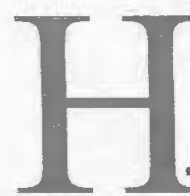

istóricamente el proceso penal se ha caracterizado por una recurrente tensión: de un lado, garantizar - la seguridad del orden jurídico mediante la persecución penal; y de otro, proteger la esfera de libertad del ciudadano' ${ }^{1}$. Visto dé una forma más amplia se materializa en el conflicto entre eficacia y garantismo.

El modelo procesal penal que ha entrado en vigencia gradual desde el 1 de enero de 2005, fija desde la constitución política (acto legislativo 03 de 2002) y desarrolla en la ley (906 de 2004) un sistema de procesamiento criminal que otorga poderes e instrumentos a la Fiscalía General de la Nación para que se dedique sin distracción (despojándola de las funciones judiciales y de directora del proceso) a la persecución penal, al tiempo que dispone como fundamento y fin el respeto por las garantías procesales de los intervinientes.

La consagraciór que como principio y derecho tiene la libertad $y$ la seguridad personal en la constitución política y los tratados internacionales sobre la materia, es expresamente recogido y detallado en diversas normas del nuevo código de procedimiento penal. El propósito central de este artículo gira en torno a identificar las herramientas o criterios de interpretación que han de aplicarse a las normas citadas, teniendo como presupuesto la evidente constitucionalización del derecho procesal penal; y también establecer los efectos jurídicos y prácticos que deben corresponder al expreso reconocimiento legal de la garantía de libertad en concordancia con la hermenéutica jurídica aplicable al asunto.

\section{CONSTITUCIONALIZACIÓN DEL DERECHO PROCESAL PENAL}

La Constitución Política de Colombia ha venido reconociendo desde su promulgación, de forma profusa, las garantías procesales. Sin embargo el Acto Legislativo 03 de 2002 ha también constitucionalizado la estructura básica del proceso penal colombiano ${ }^{2}$ reservándose para sí el constituyente, aspectos fundamentales de política criminal que tradicionalmente han correspondido al legislador dentro del amplio espectro de libertad configurativa que posee.

Sobre el punto, así también lo concluye Alejandro Aponte Cardona:

\section{"...Desde tiempo atrás hay coincidencia en la doctrina: el derecho procesal penal es derecho constitucional aplicado. No se trata apenas de una posición de principio, ni se trata de afirmaciones sustentadas en un prurito académico: se trata de la determinación constitucional de las normas procesales y del condicionamiento profundo de éstas por parte de la normativa constitucional..."}

\subsection{Bloque de constitucionalidad}

El artículo 93 de la Constitución Política alude al carácter prevalente (léase integrador) de los tratados y convenios internacionales que sobre derechos humanos haya ratificado el congreso. El artículo 3 del nuevo Código de Procedimiento Penal recoge expresamente dicho mandato, y de forma relativamente reciente, la jurisprudencia

\footnotetext{
I APONTE CARDONA, Alejandro. La detención preventiva en la nueva legislación procesal penal: hacia una prevalencia del principio de libertad. Dentro del texto Reflexiones sobre el nuevo sistema procesal penal. Bogotá: Consejo Superior de la Judicatura. Sala Administrativa. 2004. pagina 170.

${ }^{2}$ BERNAL CUELLAR Jaime y MONTEALEGRE LYNETT Eduardo. El proceso penal, Tomo I. Bogotá: Universidad Externado de Colombia, quinta edición. Julio de 2004. Paginas 113 y 114.
} 
colombiana empezó a acuñar el término bloque de constitucionalidad ${ }^{4}$ y a precisarlo en los últimos años. ${ }^{5}$

Del desarrollo doctrinario y jurisprudencial se puedeconcluirqueelbloquedeconstitucionalidad permite la incorporación de tratados de derechos humanos y derecho internacional humanitario en la práctica jurídica, y judicial en particular, lo que connstituye un avance en la medida en que permite que el país se ponga a tono con los estándares internacionales en dichos temas.

En relación con la importancia del bloque de constitucionalidad en el proceso penal colombiano, nada mejor que citar a Rodrigo Uprimny Yepes:

“..El bloque de constitucionalidad representa entonces un instrumento para que el nuevo proceso penal permita consolidar efectivamente un sistema penal que sea al mismo tiempo eficaz y garantista. Que eso se logre o no, dependerá en gran parte de los propios jueces e intervinientes en el proceso penal y de su capacidad para traducir en decisiones contretas, esos estándares abstractos de derechos humanos..."

\section{CRITERIOS DE INTERPRETACIÓN}

Consecuencia directa de la creciente constitucionalización del derecho procesal penal se refleja en la reducción del margen de posibilidades de interpretación de las normas penales por parte de los operadores jurídicos debiendo seleccionarse solo aquellos criterios hermenéuticos que se hallen conforme a la constitución.
Una de las consecuencias de adoptar criterios de dogmática constiscional se aprecia en el paso de un proceso de interpretación centrado exclusivamente en la lógica de lo racional que se materializa en la subsunción (hecho-norma) a uno fundado en la lógica de lo razonable en el que las técnicas de ponderación adquieren vital importancia ${ }^{7}$.

Así las cosas, al señalar la Constitución Política colombiana los rasgos y características básicas de un sistema de juzgamiento, que tiene fundamento en el principio acusatorio y que impone al Estado (Fiscalía) obligaciones para el ejercicio de la persecución penal y, al mismo tiempo, otorga al sujeto contra quieh se dirige dicha persecución, un catálogo de derechos y garantías dentro de la actuación procesal, resulta apenas lógico inferir la existencia de permanentes tensiones entre los principios en juego.

Pues bien, una interpretación conforme a la Constitución supone la utilización de técnicas construidas desde la dogmática, la jurisprudencia constitucional y la de los tribunales internacionales, tales como los test de igualdad, de razonabilidad, la metodología de ponderación y balanceo y la comprensión y aplicación del principio de proporcionalidad.

Debe advertirse que cada una de las técnicas señaladas se integra con las otras. Ejemplifiquemos: el test de igualdad se ha utilizado para resolver asuntos que permiten concluir si un determinado tratamiento diferente que da la ley o una actuación administrativa resulta "razonable" y/o "proporcional" a los contenidos constitucionales y al propio respeto

\footnotetext{
${ }_{5}^{4}$ Sentencia Corte Constitucional C-225 de 1995. M.P Alejandro Martínez Caballero.

5 Ver entre otras Sentencias Corte Constitucional C-774 de 2001M.P Rodrigo Escobar Gil, T-1319 de 2001, M.P. Rodrigo Uprimny Yepes y SU-058 de 2003, M.P. Eduardo Cifuentes Muñoz.

${ }^{6}$ Reffexiones sobre el nuevo sistema procesal penal. Consejo Superior de la Judicatura. Escuela Judicial Rodrigo Lara Bonilla, Bogota,2004, pagina 67.

${ }_{7}$ Atienza Manuel, Para una razonable definición de lo razonable. Doxa No 4, Universidad de Alicante, 1987. paginas 189 a 200. Citado por Bernal Cuellar y Montealegre Lynnet Eduardo. Obra citada.
} 
a la igualdad en sentido material ${ }^{8}$. El test de razonabilidad se ha utilizado para realizar juicios de "ponderación" cuando existen tensiones entre principios o derechos, debiéndose efectuar además juicios de proporcionalidad ${ }^{9}$. La metodología de la ponderación se utiliza en los mismos casos dando especial atención a las especificidades de los hechos; en muchas de las oportunidades la tensión se logra resolver sin sacrificar ninguno de los principios o derechos que están en juego (principio de armonización (concreta) $)^{10}$.

\subsection{Cláusula de favorabilidad.}

La existencia de disposiciones internas de los Estados que pueden entrar en colisión con las contenidas en los tratados internacionales, se resuelve con cláusulas especiales de interpretación contenidos en éstos últimos en las que se dispone la aplicación de la más favorable (en lo relativo a derechos o garantías) o la menos restrictiva (en lo referente a limitación de derechos) ${ }^{11}$.

La Corte Constitucional colombiana ha reconocido la ảplicación de la cláusula de favorabilidad en los siguientes términos:

\section{“(..) Ahora bien, los convenios en esta materia} suelen incorporar una cláusula hermenéutica de favorabilidad, según la cual no puede restringirse o menoscabarse ninguno de los derechos reconocidos en un Estado en virtud de su legislación interna $o$ de otros tratados internacionales, invocando como pretexto que el convenio en cuestión no los reconoce o los reconoce en menor valor. Esta Corte, en varias sentencias, ha reconocido el carácter vinculante en el ordenamiento colombiano de ésta regla de hermenéutica, seguín la cual, en caso de conflictos entre distintas normas que consagran o desarrollan los derechos humanos, el intérprete debe preferir aquella que sea más favorable al goce de los derechos. (...) ${ }^{312}$

Se deduce con claridad que en el proceso penal deben aplicarse en materia de derechos y garantías, aquellas disposiciones (legales, constitucionales o contenidas en tratados) que sean más permisivas o menos restrictivas.

\subsection{Reconocimiento a criterios de interpretación constitucional en la ley procesal:}

La Ley 906 de 2004 contiene diversas normas en las que se admiten explícitamente criterios de interpretación conforme a la Constitución y que reflejan el giro de una interpretación basada en la mera subsunción a otra fundada en criterios de razonabilidad. A modo de ejemplo transcribiremos algunas, resaltando las expresiones que incorporan los citados criterios:

ARTICULO $2^{\circ}$ LIBERTAD. Toda persona tiene derecho a que se respete su libertad. Nadie podrá ser molestado en su persona ni privado de su libertad sino en virtud de mandamiento escrito de autoridad judicial competente, emitido con las formalidades legales y por motivos previamente definidos por la ley.

Eljuezdecontroldegarantías, previasolicitud de la Fiscalía General de la Nación, ordenará la restricción de la libertad del imputado cuando resulte necesaria para garantizar su comparecencia o la preservación de la prueba o la protección de la comunidad, en

${ }^{8}$ Ver entre otras Sentencia Corte Constitucional SU-044 de 1995 M.P. Antonio Barrera Carbonell.

${ }^{9}$ Ver entre otras Sentencia Corte Constitucional C- 445 de 1995, M.P. Alejandro Martínez Caballero.

${ }^{10}$ Ver Sentencia Corte Constitucional T-622 de 1995, M.P. Eduardo Cifuentes Muñoz.

${ }^{11}$ Artículo 29 Convención Americana de Derechos Humanos y artículo 5-2 del Pacto Internacional de Derechos Civiles y políticos.

${ }_{12}$ Sentencia Corte Constitucional SU-058 de 2003, M.P. Eduardo Cifuentes Muñoz. 
especial de las víctimas. Igualmente, por petición de cualquiera de las partes, en los términos señalados en este código, dispondrá la modificación o revocación de la medida restrictiva si la circunstancias hubieren variado y la convirtieren en irrazonable o desproporcionada. (...)

ARTICULO 3․ PRELACION DE LOS TRATADOS INTERNACIONALES. ED la actuación prevalecerá lo establecido en los tratados y convenios internacionales ratificados por Colombia que traten sobre derechos humanos y que prohiban su limitación durante los estados de excepción, por formar bloque de constitucionalidad.

\section{ARTICULO 27. MODULADORES DE LA} ACTIVIDAD PROCESAL. En el desarrollo de la investigación y en el proceso penal los servidores públicos se ceñirán a criterios de necesidad, ponderación, legalidad y corrección en el comportamiento, para evitar excesos contrarios a la función pública, especialmente a la justicia.

ARTICULO* 93. CRITERIOS PARA DECRETAR MEDIDAS CAUTELARES. El juez al decretar embargos y secuestros los limitará a lo necesario, de acuerdo con las reglas establecidas en el Código de Procedimiento Civil.

El juez a solicitud del imputado, acusado o condenado, deberá examinar la necesidad de las medidas cautelares y, si lo considera pertinente, sustituirlas por otras menos gravosas $o$ reducirlas cuando sean excesivas.

ARTICULO 94. PROPORCIONALIDAD. No se podrán ordenar medidas cautelares sobre bienes del imputado o acusado cuando aparezcan desproporcionadas en relación con la gravedad del daño y la probable sentencia sobre la pretensión de reparación integral o tasación de perjuicios.
ARTICULO 295. AFIRMACTON DE LA LIBERTAD. Las disposiciones de este código que autorizan preventivamente la privación o restricción de la libertad del imputado tienen carácter excepcional; solo podrán ser interpretadas restrictivamente $y$ su aplicación debe ser necesaria, adecuada, proporcional y razonable frente a los contenidos constitucionales.

ARTICULO 296. FINALIDAD DE LA RESTRICCION DE LA LIBERTAD. LA libertad personal podrá ser afectada dentro de la actuación cuando sea necesaria para evitar la obstrucción de la justicia, o para asegurar la comparecencia def imputado al proceso, la protección de la comunidad y de las víctimas, o para el cumplimiento de la pena.

ARTICULO 308. REQUISTTOS. El juez de control de garantias, a petición del Fiscal General de la Nación o de su delegado, decretará la medida de aseguramiento cuando de los elementos materiales probatorios y evidencia física recogidos y asegurados o de la información obtenidos legalmente, se pueda inferir razonablemente que el imputado puede ser autor o participe de la conducta delictiva que se investiga, siempre y cuando se cumpla alguno de los siguientes requisitos:

1. Que la medida de aseguramiento se muestre como necesaria para evitar que el imputado obstruya el debido ejercicio de la justicia.

2. Que el imputado constituye un peligro para la seguridad de la sociedad o de la victima.

3. Que resulte probable que el imputado no comparecerá al proceso o que no cumplirá la sentencia.

ARTICULO 314. SUSTITUCIÓN DE LA DETENCIÓN PREVENTIVA. LA 
detención preventiva en establecimiento carcelario podrá sustituirse por la del lugar de residencia en los siguientes eventos.

1. Cuando para el cumplimiento de los fines previstos para la medida de aseguramiento sea suficiente la reclusión en el lugar de residencia, aspecto que será evaluado por el juez al momento de decidir sobre su imp̋osición. (...)

ARTICULO 315. MEDIDAS DE ASEGURAMIENTO NO PRIVATIVAS DE LA LIBERTAD. Cuando se proceda por delitos cuya pena principal no sea privativa de la libertad, o por delitos querellables, o cuando el mínimo de la pena señalada en la ley no exceda de cuatro (4) años, satisfechos los requisitos del articulo 308, se podrá imponer una o varias de las medidas señaladas en el artículo 307 literal $B$, siempre que sean razonables $y$ proporcionadas para el cumplimiento de las finalidades previstas.

ARTICULO 318. SOLICITUD DE REVOCATORIA. Cualquiera de las partes podrá solicitar la revocatoriaro la sustitución de la medida de aseguramiento, por una sola vez $y$ ante el juez de control de garantías que corresponda, presentando los elementos materiales probatorios o la información legalmente obtenidos que permitan inferir razonablemente que han desaparecido los requisitos del artículo 308. Contra esta decisión no procede recurso alguno.

ARTICULO319.DELACAUCION.(...)En el evento en que se demuestre la incapacidad del imputado para prestar caución prendaria, ésta podrá ser sustituida por cualquiera de las medida de aseguramiento previstas en el literal b) del artículo 307, de acuerdo con los criterios de razonabilidad, proporcionalidad ynecesidad.
Como se ve, las normas citadas exigen especiales niveles de argumentación de las partes e intervinientes (en sus peticiones) y de los jueces (en sus decisiones) en relación con la limitación de derechos fundamentales. Se podría decir que los criterios de interpretación contenidos allí, aumentan en grado sumo la discrecionalidad de los operadores judiciales, sin embargo a ello habrá de contestarse que, como ya se dijo, la jurisprudencia y doctrina constitucional han fijado subreglas que permiten decantar y precisar la textura, en principio abierta, de las disposiciones.

\subsection{Principio de libertad e interpretación.}

La consideración de la libertad compprincipio y como derecho se halla en diversas sentencias de la Corte Constitucional. Una de ellas señala:

(...) el núcleo central de la libertad personal está constituido, de una parte, por la posibilidad y el ejercicio positivo de todas las acciones dirigidas a desarrollar las aptitudes y elecciones individuales que no pugnen con los derechos de los demás ni entrañen abuso de los propios, y de otra, por la proscripción de todo acto de coerción fisica o moral que interfiera o suprima la autonomía de la persona sojuzgándola, sustituyéndola, oprimiéndola o reduciéndola indebidamente (...) $)^{\text {st3 }}$

\subsubsection{Principio pro libertate}

Muy ligado a la cláusula de favorabilidad, hallamos el principio pro libertate según elcual, el operador jurídico debe preferir la norma o interpretación de ésta que restrinja en menor grado la libertad y exige intensos niveles de justificación y argumentación cuando se adoptan decisiones que la restringen (captura o detención). Recientemente la Corte Suprema de Justicia, Sala de Casación Penal dio aplicación al citado principio cuando decidió, entre dos normas contenidas en la Ley 906 de 2004 (artículos 313-2 y 315), optar por la última en

${ }^{13}$ Sentencia Corte constitucional T-574 de 1996, M.P. Alejandro Martínez Caballero. 
cuanto comportaba una menor restricción a la libertad personal ${ }^{14}$.

\subsubsection{Afirmación de la libertad.}

Resulta incuestionable concluir que el título otorgado y el contenido del ya reseñado artículo 295 de la Ley 906 de 2004 corresponde a una extensión del principio y norma rectora del artículö "3. De aquel se deriva un mandato claro: el carácter excepcional de la privación de la libertad: "Las disposiciones de este código que autorizan preventivamente la privación o restricción de la libertad del imputado tienen carácter excepcional". En seguida la norma ordena criterios de interpretación constitucional sobre las citadas disposiciones: "solo podrán ser interpretadas restrictivamente y su aplicación debe ser necesaria, adecuada, proporcional y razonable frente a los contenidos constitucionales".

Así las cosas, la necesidad, la adecuación, la proporcionalidad, la razonabilidad y la excepcionalidad son reconocidos expresamente por el legislador en la materia como principios, a los que debe sumarse por su relación directa con ellos el de ponderación. A čontinuación se describirá el campo de aplicación de estos al momento de examinarse la viabilidad de realizar prácticas o adoptar decisiones que restrinjan la libertad de las personas.

\subsubsection{Principio de adecuación.}

Previamente ha de precisarse y reconocerse que solo a partir del pronunciamiento de la Corte Constituciona $^{15}$ en el que se concluyó que la procedenciadeladetenciónpreventivadebíaestar ligada al cumplimiento de unos determinados fines constitucionales, la judicatura nacional empezó a dejar de considerar dicha medida de aseguramiento como un asunto de imposición automática en la que simplemente imperaba la subsunción fáctica en la norma respectiva.

Sin embargo debe resaltarse que la nueva normatividadprocesalpenal ${ }^{16}$ ordenalaexigencia de vincular los fines constitucionales, no solo a la imposición de medidas de aseguramiento sino a cualquier acto de aprehensión física con fines de investigación. En ese sentido, por ejemplo, la captura solicitada por la fiscalía, previa a la formulación de imputación y por ende a la petición de medida de aseguramiento, debe ser justificada atendiendo las citadas finalidades. Así las cosas, la aplicación del principio de adecuación, exige justificar la idoneidad de la medida (captura, detención preventiva) para alcanzar cualquiera de los fines constitucionales (evitar la obstrucción de la justicia, asegurar la comparecencia del imputado al proceso, la protección de la comunidad y de las víctimas o para el cumplimiento de la pena)

\subsubsection{Principio de necesidad.}

El que una medida determinada resulte adecuada o idónea para la obtención de un fin legítimo no resulta suficiente para justificar su imposición. Debe además demostrarse que no existe otro medio alternativo que logrando también la satisfacción de la finalidad exigida, no comporte restricción del derecho o lo haga en menor grado.

\subsubsection{Principio de proporcionalidad}

La proporcionalidad entra en escena cuando se requiere confrontar los intereses en juego: el del Estado, en su ejercicio de persecución penal, y el de la persona, que puede ver amenazado un derecho fundamental. La gravedad de la conducta se constituye en un criterio de valoración para determinar la viabilidad de una medida restrictiva de la libertad o de su tiempo de duración.

\footnotetext{
${ }_{15}^{14}$ Sentencia del 20 de octubre de 2005 Radicación 24152 M.P. Jorge Luís Quintero Milanes.

${ }_{16}^{15}$ Sentencia Corte Constitucional C-774 de 2001, M.P. Rodrigo Escobar Gil.

${ }^{16}$ Artículo 296 de la ley 906 de 2004
} 


\subsubsection{Principio de ponderación}

El ejercicio de ponderación implica sopesar los principios que están en juego pero no en abstracto sino atendiendo las especificidades de los supuestos de hecho y sus circunstancias. En ese sentido la técnica de ponderación cruza cada uno de los anteriores criterios interpretativos.

\subsubsection{Principio de razonabilidad.}

La aplicación integral de los principios relacionados, constituye, sin duda, fundamento de razonabilidad. La imposición de una medida que no consulte los criterios de adecuación, necesidad y proporcionalidad se torna irrazonable. Adicionalmente la razonabilidad de una decisión que afecte la libertad personal se mide en su debida justificación y motivación, acorde con los criterios expuestos.

\subsubsection{Principio de presunción de inocencia.}

De esta relación de principios no podrá pasarse por alto el principio de presunción de inocencia ${ }^{17}$ por cuanto definitivamente constituye el soporte del alto grado de exigencia que se predica al momentto de imponer las medidas referidas. Mal podrían la captura y la detención preventiva convertirse en prácticas generales, automáticas, indiscriminadas $\mathrm{y}$ ausentes de la debida justificación si las disposiciones constitucionales están ordenando dispensar a los procesados un trato acorde con su condición de inocentes.

\section{EFECTOS DE LA NORMATIVIDAD Y SU HERMENÉUTICA}

\subsection{Principio de excepcionalidad.}

Consecuencia directade aplicar las disposiciones legales sobre privación de la libertad con una mirada constitucional, dentro de la cual se deben reconocer los estándares internacionales que han fijado los organismos competentes ${ }^{18}$, lo constituye el carácter excepcional de cualquier medida restrictiva de la libertad que adopten o soliciten las autoridades administrativas o judiciales.

\subsubsection{Efectos sobre el legislador.}

Debe destacarse que el principio de excepcionalidad vincula en primer término al legislador obligándolo a adoptar disposiciones normativas que no contravengan el carácter excepcional de las medidas restrictivas de la libertad. Así por ejemplo, la Corte Constitucional declaró inexequiblê̌s las normas de la Ley 906 de 2004 que otorgaban facultades excepcionales a la Fiscalía General de la Nación para realizar capturas urgentes sin orden previa del juez de garantías, por cuanto “(...) la norma acusada carece de claridad y precisión que exige la regulación del ejercicio de la facultad excepcional que restringe la libertad personal $(\ldots)^{m 19}$.

No debe recurrirse, por tanto, a medidas legislativas que respondan a la coyuntura de la efervescente, y a veces manipulable, opinión pública y que tiendan a disponer procedencia general de la detención preventiva para un número mayor de delitos, o fijando, por ejemplo, plazos especiales para obtener la libertad provisional atendiendo criterios tales como el de la cantidad de personas procesadas, factor que no puede ser atribuible a uno de los específicos individuos que sufre la privación de la libertad afectándosele con ello su dignidad humana.

\subsubsection{Efectos sobre los jueces.}

Son los jueces de control de garantías quienes deben sopesar la razonabilidad de las medidas

\footnotetext{
${ }_{17}$ Artículo 7 ley 906 de 2004 y 8.2 de la Convención Americana de Derechos Humanos.

${ }^{18}$ Ver Corte Interamericana de Derechos Humanos, sentencia de 12 de noviembre de 1997, caso Suárez Rosero contra Ecuador.

${ }^{19}$ Corte Constitucional Sentencia C 730 de 2005 y en el mismo sentido, Sentencia C 1001 de 2005.
} 
solicitadas por la fiscalía o practicadas por la policía de conformidad con los criterios de interpretación constitucional. En relación con la captura, debe entenderla como fenómeno complejo por cuanto debe verificar la legalidad de los actos previos a la aprehensión; del momento de la aprehensión y de aquellos que se ejercen durante el lapso de privación de la libertad para determinar que los derechos del capturado ño se hayan vulnerado. Su labor también se extiende a verificar las peticiones de la defensa cuando solicite la revocatoria de la detención preventiva, la sustitución de medida y la libertad provisional.

\subsubsection{Efectos sobre la Fiscalia}

Los fiscales delegados deben ejercer los primeros controles de constitucionalidad de las aprehensiones realizadas por la policía judicial y valorar responsable y razonablemente la necesidad de solicitar medidas que comporten limitación al derechơ de libertad.

\subsubsection{Efectos sobre la policía judicial.}

Deben los organişmó que cumplan funciones de policía judicial reformular su conducta institucional para evitar caer en la tentación de efectuar aprehensiones irrazonables y desproporcionadas, tales como las capturas masivas, estimulados por la nefasta política basada prevalentemente en los resultados operacionales o conocida como cultura del "positivo".

\subsection{Principio de favorabilidad.}

Después de los recientes pronunciamientos jurisprudenciales en los que se extendió la aplicación del principio de favorabilidad frente a la coexistencia de leyes ${ }^{20}$, se empezaron a aplicar disposiciones de la Ley 906 de 2004 que comportaban mayor favorabilidad a asuntos tramitados aún por la Ley 600 de 2000.

Así las cosas, podría concluirse que las exigencias contenidas en los artículos 295 y 296 del nuevo Código para privar de la libertad al indiciado, antes de la formulación de imputación, pueden extenderse a figuras tales como la orden de captura para indagatoria o para resolver situación jurídica. Recuérdese que para esos eventos la Ley 600 de 2000 otorga un amplio margen de discrecionalidad a la fiscalía para su procedencia, sin que se le imponga mayor carga argumentativa, lo que puede derivar en medidas arbitrarias y no respetuosas ${ }^{2}$ de los estándares internacionales y de los principios de adecuación, necesidad, proporcionalidad, ponderación, razonabilidad, presunción de inocencia y excepcionalidad.

\subsection{Un caso: el aeropirata ${ }^{21}$.}

Se ha considerado importante terminar el presente artículo sintetizando un caso de repercusión nacional que puso a prueba el nuevo sistema de juzgamiento y la cultura jurídica de los jueces.

En septiembre de 2005 el señor Porfirio Ramírez Aldana se apoderó de una aeronave de la aerolínea "Aires", con los pasajeros y la tripulación que la ocupaba. Ante la solicitud que elevara la fiscalía, el Juzgado Sexto Penal Municipal con función de control de garantías ordenó la detención preventiva considerando que "(...)el imputado constituye un peligro para la seguridad de la sociedad (...)"22

La defensa pública del imputado apeló la providencia argumentando que la fiscalía no cumplió con la exigencia legal ${ }^{23}$ de relacionar los elementos materiales de prueba que le

\footnotetext{
${ }^{20}$ Corte Suprema de Justicia, Sala de Casación Penal, autos del 4 de mayo de 2005 de M.P. Marina Pulido de Barón radicación 23567 y M.P. Yesid Ramírez Bastidas, Radicación 19094. También Corte Constitucional, Sentencia T-091 de 2006, M.P. Jaime Córdoba Triviño.

${ }_{21}$ Tomado de Prieto Vera Alberto José en su artículo Garantías constitucionales en el proceso penal colombiano del libro El Proceso Penal Acusatorio, Roles de los intervinientes, Tomo III. Bogotá Ediciones Jurídicas Andrés Morales. 2006

22 Juzgado 6 Penal Municipal de Bogotá. Auto del 13 de septiembre de 2005.
} 
permitían inferir razonablemente que el imputado podía ser autor del hecho investigado y el juez, al decidir, ignoró la omisión.

$\mathrm{Al}$ resolver el recurso, el Juzgado 52 Penal del Circuito de Bogotá ordenó anular la decisión exponiendo las siguientes razones:

\section{“(..) Consonante con un Estado Social de} Derecho, la motivación de las providencias (...) es una garantía para el procesado (...) porque tiene derecho a conocer cuál fue el criterio de apreciación y de valoración probatoria del juez, en este caso, para aplicarle una medida restrictiva de la libertad (...) si el ciudadano no conoce la manera, el mecanismo, el medio a través del cual el juez llega al conocimiento, no puede tampoco efectuar una controversia acertada y en consecuencia la determinación, la decisión judicial corre el riesgo de caer en la arbitrariedad (...) 9.4

Posteriormente la Fiscalía solicita nuevamente la detención preventiva intramuros, cuidándose de dar cumplimiento a las exigencias legales, el Juez 5 Penal Munieipal de control de garantías al adoptar la deeisión se refirió al tema de la gradualidad de la medida de aseguramiento y optó por imponerle detención domiciliaria en los siguientes términos:

\section{“(...) El juzgado califica al imputado como} una persona de mediana peligrosidad (...) que puede ser controlada con ayuda profesional de psiquiatras y psicólogos, sobre todo porque como quedó demostrado (...) el imputado es fácil de persuadir $(\ldots)^{295}$

Como reflexión del caso reseñado se destaca la utilización de criterios hermenéuticos constitucionales por parte del Juez 52 Penal del Circuito de Bogotá cuando hace alusión a la necesidad de motivación de las providencias especialmente aquellas que imponen restricción a la libertad pues de lo contrario se incurriría en arbitrariedad.

Por su parte el Juez Quinto Penal Municipal aplica el criterio de necesidad de la medida cuando advierte que la detención intramural a pesar de ser adecuada o idónea para obtener un fin constitucional, resulta excesiva y opta por la que genera una menor restricción al derecho fundamental en juego.

\section{CONCLUSIONES}

1- Al concebirse la libertad personal como principio, derecho y garantía desde la propia carta política colombiana y al definir el constituyente derivado (acto legislativo 03 de 2002) los principales rasgo del sistema procesal penal, no cabe duda concluir que se ha afianzado la constitucionalización del derecho procesal penal.

2- Un efecto concreto del citado proceso de constitucionalización lo constituye el hecho de que diversas disposiciones del nuevo código de procedimiento penal reconocen expresamente la aplicación de exigentes criterios de interpretación constitucional para la imposición de medidas que restrinjan los derechos fundamentales dentro de la actuación procesal

3- Tal como lo señala expresamente el artículo 295 de la Ley 906 de 2004, la libertad personal debe ser afirmada en desarrollo del proceso penal y la restricción de la misma debe, además de respetar el principio de legalidad, atender a los criterios de adecuación, necesidad, proporcionalidad y razonabilidad.

4- El pleno respeto a los principios y criterios señalados anteriormente debe conducir a

\footnotetext{
24 Juzgado 52 Penal del circuito de Bogota, Auto de 27 de septiembre de 2005.

25 Juzgado 5 Penal Municipal de Bogotá. Auto de 4 de octubre de 2005.
} 
que la privación de la libertad tenga carácter excepcional en el proceso penal colombiano.

5- Por último, la constitucionalización del proceso penal, así como las expresas disposiciones del nuevo Código deben invitar a los operadores judiciales a que extiendan la aplicación de los exigentes criterios que condicionan la restricción de la libertad personal a los asuntos tramitados en vigencia de la Ley 600 de 2000 , especialmente, en lo que tiene que ver con las exigencias para privar a una persona de la libertad para el acto de la indagatoria o mientras se le resuelve su situación jurídica.

\section{BIBLIOGRAFIA}

COLOMBIA. CORTE CONSTITUCIONAL. Sentencia C-024/94. Magistrado Sustanciador: ALEJANDRO MARTINEZ CABALLERO. Santafé de Bogotá, 27 de enero de 1994.

Sentencia SU-044 de 1995, Magistrado Ponente: Dr. ANTONIO BARRERA CARBONELL. Santafé de Bogotá, 9 de febrero del año 1994. .

-Sentencia C-225 de T995. Magistrado Ponente: DR. ALEJANDRO MARTÍNEZ CABALLERO. Santafé de Bogotá, 18 de mayo del año 1995.

---.-. Sentencia C-1001/05. Referencia: Magistrado Ponente: Dr. ALVARO TAFUR GALVIS. Bogotá, D. C., 3 de octubre del año 2005.

Sentencia C- 445 de 1995, Magistrado Ponente: Dr. Alejandro Martínez Caballero. Santafé de Bogotá, 4 de octubre del año 1995.

Sentencia T-622 de 1995, Magistrado Ponente: DR. EDUARDO CIFUENTES MUÑOZ. Santafé de Bogotá, 14 de diciembre del año 1995.

Sentencia T-574 de 1996, Magistrado Ponente: DR. ALEJANDRO MARTÍNEZ
CABALLERO. Santafé de Bogotá, 29 de octubre del año 1996.

Sentencia C-774/01. Magistrado Ponente: Dr. RODRIGO ESCOBAR GIL. Bogotá, D.C, 25 de julio del año 2001.

Sentencia T-1319 de 2001, Magistrado Ponente: Dr. RODRIGO UPRIMNY YEPES, Bogotá, D.C. 7 de diciembre del año 2001.

------. Sentencia SU-058/03. Magistrado Ponente: Dr. EDUARDO CIFUENTES MUÑOZ. Bogotá, D.C, 22 de Febrero del año 1993.

-----.-. Sentencia C-730/05. Magistrado Ponente: Dr. ÁLVARO TAFUR GALVIS. Bogotá, D. C., 12 de julio del año 2005.

Sentencia T-091 de 2006, Magistrado Ponente: Dr. JAIME CORDOBA TRIVIÑO. Bogotá, D. C., 10 de febrero del año 2006.

CORTE SUPREMA DE JUSTICIA. Sentencia del 20 de octubre de 2005 Radicación 24152 Magistrado Ponente: DR. Jorge Luís Quintero Milanes.

CORTE SUPREMA DE JUSTICIA. SALA DE CASACIÓN PENAL. Proceso No 23259. Magistrado Ponente: Álvaro Orlando Pérez Pinzón. veintitrés (23) de marzo del dos mil seis (2006)

CORTE SUPREMA DE JUSTICIA, SALA DE CASACIÓN PENAL, autos del 4 de mayo de 2005 de Magistrado Ponente Marina Pulido de Barón Radicación 23567 y Magistrado Ponente Yesid Ramírez Bastidas, Radicación 19094.

APONTE CARDONA Alejandro. La detención preventiva en la nueva legislación procesal penal: hacia una prevalencia del principio de libertad. Dentro del texto Reflexiones sobre el nuevo sistema procesal penal. Bogotá: Consejo Superior de la Judicatura. Sala Administrativa. Bogotá. 2004. pagina 170.$$
\text { . }
$$ 
ATIENZA Manuel. Para una razonable definición de lo razonable. Doxa No 4, Universidad de Alicante, 1987. paginas 189 a 200. Citado por Bernal Cuellar y Montealegre Lynnet Eduardo. Obra citada.

BERNAL CUELLAR, Jaime y MONTEALEGRE LYNETT, Eduardo. El proceso penal, Tomo I. Bogotá: Universidad Externado de Colombia, quinta edición. Julio de 2004. Paginas 113 y 114.

\section{CORTE}

INTERAMERICANA

DE

DERECHOS HUMANOS, Sentencia de 12 de noviembre de 1997, caso Suárez Rosero contra Ecuador. Serie C No. 35;

ESCUELA JUDICIAL Rodrigo Lara Bonilla Reflexiones sobre el nuevo sistema procesal penal. Bogota: Consejo Superior de la Judicatura. 2004, pagina 67.

ORGANIZACIÓN

DE ESTADOS AMERICANOS, COMISIÓN INTERAMERICANA DE DERECHOS HUMANOS, CORTE INTERAMERICANA
DE DERECHOS HUMANOS. Documentos básicos en materia de derechos humanos en el sistema interamericano: Convención Americana de Derechos Humanos. Artículo 7.2. - Pacto de Derechos Civiles y Políticos - Artículo 9.1. Washington: Secretaria General de la OEA, 2006. 262p.

PRIETO VERA, Alberto José. Artículo Garantías constitucionales en el proceso penal colombiano del libro El Proceso Penal Acusatorio, Roles de los intervinientes, Tomo III. Bogotá: Ediciones Jurídicas Andrés Morales. 2006.

UPRIMNY YEPES, Rodrigo. Bloque de constitucionalidad, derechos humanos y nuevo procedimiento penal. Citado en: Reflexiones sobre el nuevo sistema procesal penal. Bogotá: Consejo Superior de la Judicatura - Sala Administrativa, s.f.

ZULETA CANO, José Abad \& CARVAJAL QUINTERO, Hilda Astrid. Experiencias forenses en el sistema acusatorio. Medellín: 